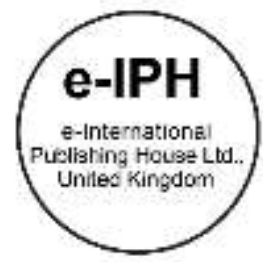

\title{
Human Factors and Attitude towards Safe Driving Scale among Young Adults in Malaysia
}

\author{
Mohamad Ghazali Masuri', Nur Ainaa Mohd Asib1, Akehsan Dahlan¹, Khairil Anuar Md Isa², \\ ${ }^{1}$ Occupational Therapy Department, Faculty of Health Sciences, UiTM Puncak Alam, Malaysia \\ ${ }^{2}$ Basic Sciences Department, Faculty of Health Sciences, UiTM Puncak Alam, 42300 Bandar Puncak Alam, Selangor, Malaysia \\ zalie222@gmail.com,ainaa.asib@gmail.com,akehsan.dahlan@yahoo.com,khairil_hpm@hotmail.com \\ Tel: +60196259314
}

\begin{abstract}
The human factor is one of the major causes that contributed to a road traffic accident (RTA). This study aims to identify the correlation between sleep duration and safe driving attitude among young adult in Malaysia. The significant relationship showed between Domain (D) 1, 4 and 5 of ASDS-46 with sleep duration (ESS). D1 (self-complaint), D4 (self-concern) has positive correlation ( $p=.110$ and .147) and D5 (driving style) has negative correlation $(p=.132)$. In conclusion, short sleep duration may influence the risk of RTA, and on-road assessment is recommended for further investigation.
\end{abstract}

Keywords: Young adult; Sleep quality; Driver's attitude; Human factors

eISSN: 2398-4287 @ 2019. The Authors. Published for AMER ABRA cE-Bs by e-International Publishing House, Ltd., UK. This is an open access article under the CC BYNC-ND license (http://creativecommons.org/licenses/by-nc-nd/4.0/). Peer-review under responsibility of AMER (Association of Malaysian Environment-Behaviour Researchers), ABRA (Association of Behavioural Researchers on Asians) and cE-Bs (Centre for Environment-Behaviour Studies), Faculty of Architecture, Planning \& Surveying, Universiti Teknologi MARA, Malaysia.

DOI: https://doi.org/10.21834/e-bpj.v4i11.1726

\subsection{Introduction}

As the years' increase, the rate of road traffic accidents (RTA) also increases that lead to fatalities and injury. Studies prove that the human factor was a significant contributor to RTA. This study is interested in investigating the elements of cognitive ergonomics such as mental process, perception memory, reasoning and motor response related to the driving environment in Malaysia. The driver's attitudes become the main issues to keep safety on the road during driving. World Health Organization (2015) reported that global road death occurs around $85 \%$ and $90 \%$ of the disability-adjusted life years lost due to crashes. Road traffic injuries were currently estimated to be the ninth leading cause of death across all age groups globally and are predicted to become the seventh leading cause of death by 2030 as reported in Global Status Report on Road Safety 2015. Surprisingly, road traffic injuries are the leading in the ranking that causes of death among those aged 15-29. More than 50\% of deaths are among young adults in the age range of $15-44$ years. The risk of injury and fatality reported among this group of drivers as they were engaging in unsafe driving (Kamal, Masuri, Dahlan, \& Isa, 2015). The connections of young adults in RTA are due to several factors such as attitudes while driving, skills, personality and sleep issues. According to Zwahlen, Jackowski, and Pfäffli, (2016), sleepiness has a significant impact on road safety, where $20 \%$ of traffic accidents, were caused by drowsiness. The crash occurs more frequently in the afternoon and at night due to sleep deprivation. Sleep deprivation usually caused by prolonged wakefulness, shift work or poor sleep quality. This poor sleep quality may lead to lack of attention, speeding and other risky behaviours. This human factor was believed as the associated contributing factors that may result in road traffic accidents. There were many causes of a crash, either it is due to primary or secondary factors. These factors were known as a human factor where Masuri, Dahlan, Danis and Md Isa (2015) stated that studies prove it was a significant contributor to RTA. For instance, the driver's attitudes become the main issues to keep safety on the road during driving. Through the presented manners while driving, the tendency for the drivers to commit traffic offences also could be observed. Factors such as speeding, using a mobile phone and not wearing a seat belt are considered as a contributing factor for injury and fatality (Masuri, Dahlan, Danis, \& Md Isa, 2015; Md Isa et al., 2012 \&

eISSN: 2398-4287 @ 2019. The Authors. Published for AMER ABRA cE-Bs by e-International Publishing House, Ltd., UK. This is an open access article under the CC BYNC-ND license (http://creativecommons.org/licenses/by-nc-nd/4.0/). Peer-review under responsibility of AMER (Association of Malaysian Environment-Behaviour Researchers), ABRA (Association of Behavioural Researchers on Asians) and cE-Bs (Centre for Environment-Behaviour Studies), Faculty of Architecture, Planning \& Surveying, Universiti Teknologi MARA, Malaysia.

DOI: https://doi.org/10.21834/e-bpj.v4i11.1726 
Masuri, Abdul Samad, Dahlan \& Md Isa 2019). However, this study focuses on the two human factors that may contribute to RTA, which are attitudes of drivers and sleep issues.

\subsection{Literature review}

Driving is one of the instrumental activities of daily living, which involved complex cognitive process, and motor coordination of eyeshand-foot and failure to perform these may lead to RTA (Kamal, Masuri, Dahlan, \& Isa, 2015). According to Road Transport Department Malaysia (2017), a statistic shown that the number of existing vehicles on the road in Malaysia is over 15 million in the year of 2014 and increase more than 18 million in the year 2015. According to Ministry of Transport Malaysia (MOT), in 2015, the total number of road accidents by states in Malaysia is 489,696 compared with the previous year with only 476,196 as reported in Transport Statistic Malaysia 2015. The number of RTA among young adult had become a frightening issue in Malaysia as the number of injuries keep arising every year and may contribute to a significant effect on people quality of life (Wan Ahmad Kamal, Masuri, Dahlan, \& Md Isa, 2015). According to Nasa (2014), RTA had been identified as the leading factor of fatalities after coronary/heart disease, stroke, influenza and pneumonia. According to the Malaysian Institute of Road Safety Research (MIROS), an average of 18 people was killed on Malaysian roads daily, and it is expected to rise to 29 by 2020. MIROS reported that the fatalities had been predicted where in the year 2015 there are 8,760 fatalities, and this figure is expected to rise to 10, 716 in the year 2020. Besides, the Royal Malaysia Police (PDRM) reported that the number of deaths due to road accidents is 6,706 in the year 2015, with an average of 18 cases of death per day. Individual with age range between 16 years old until 20 years old recorded highest number with 934 cases, followed by age between 21 until 25 years old (828 cases), 26 until 30 years old (641 cases), 31 - 35 years old (579 cases), and others are 36 years old and above. Studies prove that the human factor was a significant contributor to RTA. This study is interested in investigating the elements of cognitive ergonomics such as mental process, perception memory, reasoning and motor response related to the driving environment in Malaysia. The driver's attitudes become the main issues to keep safety on the road during driving. Attitudes can be presented both in positive and negative form and always display the unsynchronized, but both attitudes and behaviours are sensitive to the social situation although not in straightforward (Masuri, Dahlan, Danis, \& Md Isa, 2015). Mather (2009) stated that driving is related to the social phenomenon, as social psychology tends to influence the human factor of driving. The previous study by Danciu, Popa, Micle, \& Preda (2012) found that kind and the anxious individual tends to have high risk related to traffic accidents, which have a positive attitude towards traffic safety. In contrast, an individual who has a high score in seeking sensation and normlessness have low risk related to traffic accidents, which shows a negative attitude towards traffic safety, and more risk-taking in traffic were reported. Therefore, the safety on the road is relying on the attitudes of the drivers during driving. Hence, drivers should beware upon this potential issue to prevent danger from road, obstacles and other road users. Sleep is one of the daily activities that must be engaged for a human. Sleep is a complex of physiologic and processes of behaviour that involve unresponsiveness to the environment (Carskadon \& Dement, 2011). Sufficient sleep is very crucial for each person to enable him or her to become enthusiastic on the next day. Hirshkowitz et al. (2015) reported that the National Sleep Foundation recommended the sleep duration for young adults should be 7 to 9 hours and appropriately for at least 6 hours. This is believed able to enhance the optimal performance of an individual in their daily routine. However, with the anxious lifestyle, sleep seems to be unimportant due to several issues where young adult was busily dealing with facing new challenges in their life that required them to be responsible for himself, adjust new schedule and stress-related with academic (Say, Lai, \& Say, 2016), occupation/ jobs and independence of living away from home as well as active social life (Radek \& Kaprelian, 2013). Therefore, with these current lifestyle, they forced to adjust their sleeping time as well as sleeping habits that cause difficulty to sleep and become one of the most sleepdeprived within age group (Say, Lai \& Say 2016) that can result to sleepiness where the longer someone remains awake, the higher the need to sleep and the more difficult it is to resist falling asleep (Nguyen, 2002). Falling asleep may reduce alertness while driving and can cause a severe incident that may affect the entire life of the person. Mental components that affect alertness are cognitive, time responds, stress and mental status (Masuri, Dahlan, Danis, \& Isa, 2015). According to Smith, Carrington and Trinder (2005), sleepiness is a significant contributor to a car accident and resulting high mortality and morbidity than other accident where the study showed that young adult driver is usually at risk for sleepiness related car crashes. The previous study demonstrated that every year, 4-8\% of drivers fall asleep during driving (Abe, Komada, Nishida, Hayashida \& Inoue, 2010) and this may lead to accidents where the drivers unable to manoeuvre the vehicle consciously. The driver will run off the road or crashes, either with vehicles or with objects (Abe et al., 2010). Furthermore, Philips and Sagberg (2013) reported that 2.2 and 3.9 per cent of the accidents caused by the sleepiness and tiredness behind the wheel. Lemke et al. (2016) found that the duration of sleep is a well-established cause in driving performance. Excessive daytime sleepiness may contribute to poor night sleep quality. Also, Komada, Asaoka, Abe and Inoue (2013) also stated that sleepiness is the leading cause of traffic accidents due to human error where the person who sleeps less than 6 hour will raise the risk of traffic accidents.

\subsection{Methodology}

A cross-sectional study was conducted to identify the correlation between duration of sleep and attitudes of the driver as well as the relationship between sleepiness and attitudes of driving among young adult in Malaysia. A simple random sampling was used as it targeting the subjects among young adults in Malaysia. Two sets of self-administered questionnaires that are; Attitude towards Safe Driving Scale (ASDS-46) to identify the attitudes of young adults during driving and Epworth Sleepiness Scale (ESS) to measure daytime sleepiness. These questionnaires had been distributed among young adults in Peninsular Malaysia based on inclusion criteria that are young adult age between 18- 35 years old, that have licenses, which are currently driving and can understand English. 


\subsection{Findings}

A total number of distributed questionnaires was 328 and 141 were recorded from an online survey (Google docs). Only 308 respondents had returned the completed questionnaires. Thus, total respondents who completed the questionnaires were 449 , where $147(32.7 \%)$ of the respondents were male, and $302(67.3 \%)$ were female with age range between 18 to 35 years old. Table 1 shows the details of the respondent's demographic data.

\begin{tabular}{ll} 
& Table 1. Demographic data (N=449) \\
\hline Demographic data & Frequency (percentage) \\
\hline Gender & $147(32.7)$ \\
Male & $302(67.3)$ \\
Female & $342(76.2)$ \\
\hline Age & $92(20.5)$ \\
$18-23$ & $15(3.3)$ \\
$24-29$ & \\
$30-35$ & $265(59.0)$ \\
\hline Area of living & $159(35.4)$ \\
Urban & $25(5.6)$ \\
Rural & \\
Others & $380(84.6)$ \\
\hline Race & $43(9.6)$ \\
Malay & $15(3.3)$ \\
Chinese & $11(2.4)$ \\
Indian & \\
Others & $411(91.5)$ \\
\hline Marital status & $34(7.6)$ \\
Single & $4(0.9)$ \\
Married & $14(3.1)$ \\
Others & $81(18.0)$ \\
\hline Driving license class & $337(75.1)$ \\
B & $5(1.1)$ \\
B2 & $149(33.2)$ \\
D & $89(19.8)$ \\
Others & $56(12.5)$ \\
\hline Driving purpose & $155(34.5)$ \\
Study & $382(85.1)$ \\
Working & $67(14.9)$ \\
Recreational & $319(71.0)$ \\
Others & $130(29.0)$ \\
\hline Involve in a traffic accident & \\
None & \\
Yes & Witness in a traffic accident \\
None & \\
Yes & \\
\hline & \\
\hline & \\
\hline
\end{tabular}

Table 2 presents the total score of ASDS-46 and risk level for each domain that consists of means, standard deviation, minimum, maximum and sum of the high/low-risk score. The value of Cronbach's Alpha is 0.839 , which stand for high reliability (Masuri et al., 2016). The mean score for each domain was $(45.28,45.03,21.30,21.20,12.23$ and 13.51$)$. In D1, there are $50.8 \%$ are respondent who lows risk and $49.2 \%$ high risk. For D2, $47.9 \%$ of the respondents are low risk, and $52.1 \%$ are high risk. For D3, D4, D5, and D6, the lower risk were as followed 49.2, 49.4, 45 and 45.9 while the high risk is 50.8, 50.6,55 and 54.1 .

Table 2.ASDS-46 score for six domains

\begin{tabular}{lcccccc}
\hline \multicolumn{1}{c}{ ASDS } & D1 & D2 & D3 & D4 & D5 & D6 \\
\hline Mean & 45.28 & 45.03 & 21.30 & 21.20 & 12.23 & 13.51 \\
Std. Deviation & 10.27 & 6.47 & 3.91 & 3.10 & 2.95 & 2.69 \\
Minimum & 13.00 & 24.00 & 6.00 & 5.00 & 4.00 & 4.00 \\
Maximum & 65.00 & 60.00 & 30.00 & 25.00 & 20.00 & 20.00 \\
High risk & $221(49.2)$ & $234(52.1)$ & $228(50.8)$ & $227(50.6)$ & $247(55.0)$ & $234(54.1)$ \\
Low risk & $228(50.8)$ & $215(47.9)$ & $221(49.2)$ & $222(49.4)$ & $202(45.0)$ & $206(45.9)$ \\
\hline (D1: self-compliant, D2: self-confidence, D3: self-benefit, D4: self-concern, D5: driving style, D6: self-preparedness
\end{tabular}

Table 3 below presents the frequency of the risk of the respondents for each domain of ASDS-46 that are high risk and low risk toward RTA In D1, there are $30.8 \%$ are respondent who lows risk and $49.2 \%$ high risk. For D2, $47.9 \%$ of the respondents are low risk, and $52.1 \%$ are high risk. For D3, D4, D5, and D6, the lower risk were as followed 49.2, 49.4, 45and 45.9 while the high risk is 50.8, 50.6,55 and 54.1.

Table 3. Frequency \& Percentage risk level of ASDS-46 for each domain

\begin{tabular}{lllllll}
\hline $\begin{array}{l}\text { ASDS-46 } \\
\text { Domain }\end{array}$ & D1 & D2 & D3 & D4 & D5 & D6 \\
\hline High risk & $221(49.2)$ & $234(52.1)$ & $228(50.8)$ & $227(50.6)$ & $247(55.0)$ & $234(54.1)$ \\
\hline
\end{tabular}




\begin{tabular}{lllllll}
\hline Low risk & $228(50.8)$ & $215(47.9)$ & $221(49.2)$ & $222(49.4)$ & $202(45.0)$ & $206(45.9)$ \\
\hline
\end{tabular}

Table 4 presented the demographic information for the sleep of the respondents. Most of the respondent sleep within or exceed than 6 hours $56.6 \%(n=254)$ while only $43.4 \%(n=196)$ of the respondent sleep below than 6 hours. However, only $41.4 \%$ of the respondent has an actual sleep for below than 6 hours and $58.6 \%$ more than 6 hours. More than half of the respondent performs sleep at night compare during the daytime, which presents $93.1 \%$, followed by $6.9 \%$ respectively.

Table 4. ESS Scoring

\begin{tabular}{lc}
\multicolumn{2}{c}{ Table 4. ESS Scoring } \\
\hline Demographic data ESS & Frequency (percentage) \\
\hline Duration of Sleep & $195(43.4)$ \\
Less than 6 hour & $254(56.6)$ \\
Within/more than 6 hour & \\
& \\
\hline Nature of Sleep & $418(93.1)$ \\
Prior at night & $31(6.9)$ \\
Prior during daytime & \\
\hline Actual Sleep Hours & $186(41.4)$ \\
$<6$ hours & $263(58.6)$ \\
Within or $>6$ hours & \\
\hline
\end{tabular}

From the total sum of the eight questions of situations in ESS, the raw score then convert into three scales, which indicate the level of sleepiness scale of the respondents (reasonable, moderate and severe). From the result, the level of sleepiness of the respondent had been calculated and shows most of the respondent has a regular sleep or get enough sleep $56 \%(n=247)$ followed by moderate excessive daytime sleepiness $39.6 \%(n=178)$ and severe excessive daytime sleepiness $5.3 \%(n=24)$. Table 4 shows the mean score for each domain of ASDS-46 between respondents who have the duration of sleep less than six hours compare with who had asleep within and more than six hours. Respondents who have a sleep within or more than six hours have high mean for each domain of ASDS-46 except for domain five which shows that respondents who have slept less than six hours score high than who has a sleep within or more than six hours.

Table 5 shows the mean score for each domain of ASDS-46 between respondents who have a duration of sleep less than six hours compare with who had asleep within and more than six hours. Respondents who have a sleep within or more than six hours have high mean for each domain of ASDS-46 except for domain five which shows that respondents who have slept less than six hours score high than who has a sleep within or more than six hours.

Table 5. Mean of sleep duration between domains of ASDS-46

\begin{tabular}{l|c|ccccccc}
\hline & \multicolumn{2}{c}{ ASDS domain } & & D1 & D2 & D3 & D4 & D5 \\
\hline \multirow{3}{*}{$\begin{array}{l}\text { Duration } \\
\text { of sleep }\end{array}$} & $<6$ hours & Mean & 43.99 & 45.04 & 21.15 & 20.68 & 12.67 \\
& $\mathrm{~N}=195$ & (S.D.) & 10.71 & 6.56 & 3.98 & 3.19 & 2.84 \\
\cline { 2 - 8 } & $\geq \mathbf{6}$ hours & Mean & 46.26 & 45.03 & 21.40 & 21.60 & 11.89 & 13.53 \\
& $\mathrm{~N}=\mathbf{2 5 4}$ & (S.D.) & 9.82 & 21.40 & 3.86 & 21.20 & 2.99 \\
\hline
\end{tabular}

Table 6 shows that there is a significant correlation between duration of sleep and ASDS-46. These found that duration of sleep correlates with D1, D4 and D5 where the correlation was a label in bold. Duration of sleep has a positive relationship with D1, and D4 of ASDS-46 domain with $r$ value are .110 and .147, respectively ( $p=.020$ and .002). These show that respondents who have a duration of sleep less than six hours have high risk in self-compliant and self-concern that increase the risk to involve in RTA offences. However, length of sleep is negatively correlated with driving style $(p=.005)$ which indicates that respondents who have a sleep within or more than six hours, they have high risk and increase the tendency to involve in RTA of-fences as they do not want to change their driving style that may lead to offences.

Table 6. Correlation between duration of sleep and ASDS-46 domains

\begin{tabular}{|c|c|c|c|c|c|c|c|}
\hline \multicolumn{2}{|c|}{ ASDS domain } & D1 & $\mathrm{D} 2$ & D3 & D4 & D5 & D6 \\
\hline \multirow{2}{*}{$\begin{array}{l}\text { Duration Of } \\
\text { sleep }\end{array}$} & Pearson & $.110^{*}$ & -.001 & .032 & $.147^{* *}$ & $-.132^{*}$ & -.005 \\
\hline & Sig. (2-tailed) & .020 & .979 & .498 & .002 & .005 & .912 \\
\hline
\end{tabular}

Table 7 presented the mean of each of ESS level (healthy sleep, moderate excessive daytime sleepiness and severe excessive daytime sleepiness) for each of the domain of ASDS-46. The table also shows that there is no correlation between the score of ESS with ASDS-46 domains. The value of significant level does not show any significant correlation, which is $P<0.001$. Hence, the null hypothesis is accepted. The score of ESS is not significantly different from ASDS-46. The findings showed that ASDS-46 and ESS have a high and moderate level of reliability as the Cronbach's Alpha value is .91 and .76, respectively. 
Table 7. Mean and correlation between ESS level and ASDS-46 domains

\begin{tabular}{|c|c|c|c|c|c|c|c|}
\hline & DS-46 domain & D1 & $\mathrm{D} 2$ & D3 & D4 & D5 & D6 \\
\hline \multirow{3}{*}{$\begin{array}{l}\text { Mean of ESS } \\
\text { level }\end{array}$} & Normal & 45.37 & 45.01 & 21.11 & 21.18 & 12.23 & 13.59 \\
\hline & Moderate & 45.30 & 45.15 & 21.53 & 21.29 & 12.03 & 13.46 \\
\hline & Severe & 44.17 & 44.33 & 21.46 & 20.80 & 13.67 & 13.13 \\
\hline \multirow[t]{2}{*}{ ESS score } & Pearson Correlation ( $\mathrm{r}$ ) & -.018 & -.007 & .047 & -.006 & .043 & -.040 \\
\hline & Sig. (2tailed) & 707 & .883 & .323 & .903 & .361 & .398 \\
\hline
\end{tabular}

${ }^{* *}$ Correlation is significant at the 0.01 level (2-tailed).

\subsection{Discussion}

This study had explained that sleep duration is very critical. Individuals have a period of sleep for less than six hours, and they have a high risk in self-compliant and self-concern that increase the risk to involve in RTA offences. A study by Maia, Grandner, Findley and Gurubhagavatula (2013) also support this study finding where individual who has sleep duration less than six hours likely to affect driving performance as they reported drowsy during driving. The current research by Matsui, Sakuma, Ishigooka and Inoue (2017) also found insufficient sleep becomes the contributor of drowsiness while driving and sleepiness-related vehicle accidents. They also explain that other factors such as longer monthly driving distance and shorter nocturnal sleep duration lead to sleepiness on the wheel that contributes to crashes. However, duration of sleep has a negative correlation with driving style, which indicates that respondents who have a sleep within or more than six hours, they have high risk and increase the tendency to involve in RTA offences, as they do not want to change their driving style that may lead to offences. Meanwhile, daytime sleepiness did not influence attitudes of driving among young adults. However, a study by Turkington showed that ESS correlated with "near-miss accidents". This contrast with this study and those reported Pichel, Zamarron, Magan and Rodriguez (2006) which found no such significant relationship between ESS and driving simulator performance. According to Horstmann, Hess, Bassetti, Gugger and Mathis (2000), this may due to the questions in ESS not directly related with the driving situation or it more sensitive to the groups with sleep disorders. Nevertheless, there is a significant correlation between the questions of ESS that consist of eight situations with a domain of ASDS-46. These correlations are presented between Question 4, 6, 7 and 8 with D1, D2, D4, D5 and D6 of ASDS-46. This result can conclude there is a significant relationship between the different situations of dozing or daytime sleepiness with attitudes of driving that may influence the increasing number of traffic offences and have high tendency to contribute to vehicle accidents rates. Attitudes and sleepiness may indicate an association that becomes one of the factors, which help to a high number of a road traffic accident. Sufficient amount of sleep may prevent drowsiness and low the chance of dozing during the daytime. Therefore, this shows that human factors, specifically from a cognitive perspective, may affect the performance of an individual in driving.

\subsection{Conclusion}

As a conclusion, short sleep duration may influence the risk of RTA. Even though daytime sleepiness may not show association directly with driving attitudes, it may affect driving performance in real on-road driving. However, in certain circumstances, tiredness may affect the performance in driving as well as other daily performance. High chance of dozing in a specific day-to-day situation may contribute to the attitudes that have the potential to lead the individual to commit traffic offences, thus influence the rate of vehicle accidents. Employer and higher authorities, including healthcare providers, should deliberate active precaution in managing this issue. Factors such as changes in sleeping schedule or habits and awareness program may help to improve sleep quality as well as daily functional performance. The occupational therapist uses the principle of occupational science in their daily practice. Occupational science is a terminology that is referring to the science of everyday living. Occupational science emphases on the benefits of productive, social and physical activity in people's ordinary lives. It is dedicated to learning how commitment in the occupation can address global health concerns by promoting health, well-being and quality of life across the lifespan. Finally, occupational therapy and other healthcare professionals may collaborate to contribute to driving rehabilitation as it may help to enhance the quality of life.

\section{Acknowledgements}

The highest appreciation goes to the Ministry of Higher Education Malaysia (MoHE), Malaysian Institute of Road Safety Research (MIROS), Research Management Centre (RMC) Universiti Teknologi MARA (UiTM), CoRe Management Science, OPERA RIG, and all staff of the Faculty of Health Sciences UiTM Puncak Alam for continuous support in staff research and development. Lastly, specially mentioned to our beloved friend and research team; Allahyarham Anniz Fazli Ibrahim Bajunid. This study was funded under LESTARI grant by UiTM - (600IRMI/Dana KCM 5/3/LESTARI (154/2017).

\section{References}

Abe, T., Komada, Y., Nishida, Y., Hayashida, K., \& loue, Y. (2010). Short sleep duration and long spells of driving are associated with the occurrence of Japanese drivers' rear-end collisions and single-car accidents. Journal of Sleep Research, 19(2), 310-316. doi:10.1111/j.1365-2869.2009.00806.x 
Bates, L. J., Davey, J., Watson, B., King, M. J., \& Armstrong, K. (2014). Factors Contributing to Crashes among Young Drivers. Sultan Qaboos University Med Journal, 14(3), 297-305.

Carskadon, M. A., \& Dement, W. C. (2011). Chapter 2 - Normal Human Sleep : An Overview, 16-26.

Chuen, O. C., Karim, M. R., \& Yusoff, S. (2014). Mode Choice between Private and Public Transport in Klang Valley, Malaysia, 2014(Figure 1), 7-9.

Danciu, B., Popa, C., Micle, M. I., \& Preda, G. (2012). Psychological risk factors for road safety. Procedia - Social and Behavioral Sciences, 33, 363-367. doi:10.1016/j.sbspro.2012.01.144

Garbarino, S., Lino, N., Beelke, M., Carli, F. D., \& Ferrillo, F. (2001). The Contributing Role of Sleepiness in Highway Vehicle Accidents. Sleep, 24(2), 201-206. doi:10.1093/sleep/24.2.201

Hirshkowitz, M., Whiton, K., Albert, S. M., Alessi, C., Bruni, O., DonCarlos, L., ... Adams Hillard, P. J. (2015). National Sleep Foundation's sleep time duration recommendations: methodology and results summary. Sleep Health, 1(1), 40-43. doi:10.1016/j.sleh.2014.12.010

Horsman, G., \& Conniss, L. R. (2015). Investigating evidence of mobile phone usage by drivers in road traffic accidents. Digital Investigation, 12, S30-S37. doi:10.1016/j.diin.2015.01.008

Horstmann, S., Hess, C. W., Bassetti, C., Gugger, M., \& Mathis, J. (2000). Sleepiness-Related Accidents in Sleep Apnea Patients. Sleep, $23(3), 1-7$. doi:10.1093/sleep/23.3.1e

lliescu, D., \& Sârbescu, P. (2013). The relationship of dangerous driving with traffic offenses: A study on an adapted measure of dangerous driving. Accident Analysis \& Prevention, 51, 33-41. doi:10.1016/j.aap.2012.10.014

Kamal, W. N., Masuri, M. G., Dahlan, A., \& Isa, K. A. (2015). Seat Belt Compliance and Quality of Life among Educated Young Adults in an Urban University. Procedia Social and Behavioral Sciences, 202, 442-447. doi:10.1016/j.sbspro.2015.08.249

Kendzerska, T. B., Smith, P. M., Brignardello-Petersen, R., Leung, R. S., \& Tomlinson, G. A. (2014). Evaluation of the measurement properties of the Epworth sleepiness scale: A systematic review. Sleep Medicine Reviews, 18(4), 321-331. doi: 10.1016/j.smrv.2013.08.002

Komada, Y., Asaoka, S., Abe, T., \& Inoue, Y. (2013). Short sleep duration, sleep disorders, and traffic accidents. IATSSR, 37(1), 1-7. http://doi.org/10.1016/j.iatssr.2013.06.001

Lemke, M. K., Apostolopoulos, Y., Hege, A., Sönmez, S., \& Wideman, L. (2016). Understanding the role of sleep quality and sleep duration in commercial driving safety. Accident Analysis \& Prevention, 97, 79-86. doi: 10.1016/j.aap.2016.08.024

Maia, Q., Grandner, M. A., Findley, J., \& Gurubhagavatula, I. (2013). Short and long sleep duration and risk of drowsy driving and the role of subjective sleep insufficiency. Accident Analysis \& Prevention, 59, 618-622. doi:10.1016/j.aap.2013.07.028

Masuri, M. G., Dahlan, A., Danis, A., \& Md Isa, K. A. (2016). Attitude towards Safe Driving Scale (ASDS) As a Future Predictor in Determining a Young Adult Quality Of Life: Part I. Procedia - Social and Behavioral Sciences,234,390-39 doi:10.1016/j.sbspro.2016.10.256.

Masuri, M. G., Abang Mustaffa, D. N., Dahlan, A., \& Md. Isa, K. A. (2016). The Intention in Speeding Behavior between Low and High Intended Young Driver in Urban University. Environment-Behaviour Proceedings Journal, 1(1), 330. doi:10.21834/e-bpj.v1i1.229

Masuri, M. G., Dahlan, A., Danis, A., \& Isa, K. A. (2015). Public Participation in Shaping Better Road Users in Malaysia. Procedia - Social and Behavioral Sciences, 168, 341-348. doi:10.1016/j.sbspro.2014.10.239

Masuri, M. G., Dahlan, A., Danis, A., \& Isa, K. A. (2015). Regeneration of Road System in the Urban Environment: Will Rehabilitation Components Orientate Road Users? Procedia - Social and Behavioral Sciences, 170, 700-708. doi:10.1016/j.sbspro.2015.01.072

Masuri, M. G., Dahlan, A., Danis, A., \& Isa, K. A. (2016). Attitude towards Safe Driving Scale (ASDS) As a Future Predictor in Determining a Young Adult Quality Of Life: Part I. Procedia - Social and Behavioral Sciences, 234, 390-397. doi:10.1016/j.sbspro.2016.10.256

Masuri, M. G., Dahlan, A., Danis, A., \& Md Isa, K. A. (2017). Attitude towards Safe Driving Scale (ASDS-46) as a Future Predictor in Determining a Young Adult Quality Of Life: Part II. Environment-Behaviour Proceedings Journal, 2(5), 363. doi:10.21834/e-bpj.v2i5.705

Masuri, M. G., Dahlan, A., Danis, A., \& Md Isa, K. A. (2018). Attitude towards Safe Driving Scale (ASDS-46) as a Predictor of Young Adult Quality Of Life. Asian Journal of Quality of Life, 3(11), 11. doi:10.21834/ajqol.v3i11.117

Masuri, M. G., Isa, K. A., \& Tahir, M. P. (2012). Children, Youth and Road Environment: Road Traffic Accident. Procedia - Social and Behavioral Sciences, 38, $213-218$. doi:10.1016/j.sbspro.2012.03.342

Mather, R. D. (2009). Social Cognitive Human Factors of Automobile Driving. In In: Road Traffic; Safety, Modelling, and Impacts (pp. 385-401).

Matsui, K., Sasai-Sakuma, T., Ishigooka, J., \& Inoue, Y. (2017). Insufficient sleep rather than the apnea-hypopnea index can be associated with sleepiness-related driving problems of Japanese obstructive sleep apnea syndrome patients residing in metropolitan areas. Sleep Medicine, 33, 19-22. doi:10.1016/j.sleep.2016.07.022

Md Isa, K. A., Masuri, M. G., Abd Aziz, N. A., Isa, N. N., Hazali, N., Tahir, M. P., ... Fansuri, H. (2012). Mobile Phone Usage Behaviour while Driving among Educated Young Adults in the Urban University. Procedia - Social and Behavioral Sciences, 36, 414-420. doi:10.1016/j.sbspro.2012.03.045

Miletin, M. S., \& Hanly, P. J. (2003). Measurement properties of the Epworth sleepiness scale. Sleep Medicine, 4(3), 195-199. doi:10.1016/s1389-9457(03)00031-5 
Ministry Of Transport. (2015). Transport Statistic Malaysia 2015 (0128-2778). Retrieved from Ministry Of Transport Malaysia website: http://www.mot.gov.my/my/Statistik\%20Tahunan\%20Pengangkutan/Statistik\%20Pengangkutan\%20Malaysia\%202015.pdf

Nasa, A. (2014, July 9). Malaysia ranked 20th in road deaths. New Straits Times [Kuala Lumpur]. Retrieved from http://www.nst.com.my/news/2015/09/malaysia-ranked20th-road-deaths

Nguyen, J. L. (2002). The Effects of Reversing Sleep-Wake Cycles on Sleep and Fatigue on The Crew of USS John C. Stennis (Master's thesis, Naval Postgraduate School). Retrieved from http://www.dtic.mil/dtic/tr/fulltext/u2/a407035.pdf.

Phillips, R. O., \& Sagberg, F. (2013). Road accidents caused by sleepy drivers: Update of a Norwegian survey. Accident Analysis \& Prevention, 50, 138-146. doi: 10.1016/j.aap.2012.04.003

Pichel, F., Zamarrón, C., Magán, F., \& Rodríguez, J. R. (2006). Sustained attention measurements in obstructive sleep apnea and risk of traffic accidents. Respiratory Medicine, 100(6), 1020-1027. doi:10.1016/j.rmed.2005.09.036.

Radek, K. S., \& Kaprelian, J. (2013). Emerging Adult Sleep Quality: Health and Academic Performance Factors of Assessment. http://doi.org/10.4172/2167-0277.1000112

Redhwan, \& Karim AJ. (2010). Knowledge, Attitude and Practice Towards Road Traffic Regulations Among University Students, Malaysia. The International Medical Journal Malaysia (IMJM), 9(2), 29-34.

Say, Y., Lai, P., \& Say, Y. (2016). Associated Factors of Sleep Quality and Behavior among Students of Two Tertiary Institutions in Northern Malaysia Associated Factors of Sleep Quality and Behavior among Students of Two Tertiary Institutions in Northern Malaysia, (August).

Smith, S., Carrington, M., \& Trinder, J. (2005). Subjective and predicted sleepiness while driving in young adults. Accident Analysis \& Prevention, 37(6), 1066-1073. doi:10.1016/j.aap.2005.06.008

Verster, J. C., Kayumov, L., Lowe, A. D., Santana, M. G., Tufik, S., \& Mello, M. T. (2006). Sleep disorders, sleepiness and traffic safety : a public health menace, 39 863-871.

Wahida, A. B., Ilhamah, O., Suffian, A. M., Aimi, M. F., Norlen, M., \& Wong, S. V. (2013). Obstructive sleep apnea among commercial vehicle drivers in Malaysia: Issues and initiatives. Health, 05(08), 80-86. doi:10.4236/health.2013.58a2012

Wan Ahmad Kamal, W. N. H., Masuri, M. G., Dahlan, A., \& Md Isa, K. A. (2015). Seat Belt Compliance and Quality of Life among Educated Young Adults in an Urban University. Procedia - Social and Behavioral Sciences, 202, 442-447. doi:10.1016/j.sbspro.2015.08.249

World Health Organization. (2015). Global Status Report On Road Safety 2015.Geneva, Switzerland: http://www.who.int/violence_injury_prevention/road_safety_status/2015/en/

Zhang, T., \& Chan, A. H. (2014). Sleepiness and the risk of road accidents for professional drivers: A systematic review and meta-analysis of retrospective studies. Safety Science, 70, 180-188. doi:10.1016/j.ssci.2014.05.022

Zwahlen, D., Jackowski, C., \& Pfäffli, M. (2016). Sleepiness, driving, and motor vehicle accidents: A questionnaire 